\title{
Torta de girassol em suplementos múltiplos para bovinos em pastejo no período seco do ano: desempenho produtivo e viabilidade econômica ${ }^{1}$
}

\author{
Sunflower cake in multiple supplements for cattle grazing in the dry season: growth \\ performance and economic viability
}

\author{
MESACASA, Allan Cristian ${ }^{2 *}$; ZERVOUDAKIS, Joanis Tilemahos ${ }^{3}$; \\ ZERVOUDAKIS, Luciana Keiko Hatamoto ${ }^{4}$; CABRAL, Luciano da Silva ${ }^{5}$; ABREU, \\ Joadil Gonçalves de ${ }^{5}$, LEONEL, Fernando de Paula ${ }^{6}$; SILVA, Renata Pereira da ${ }^{1}$; \\ SILVA, Rafael Ferrato Gonçalves da ${ }^{1}$
}

\footnotetext{
${ }^{1}$ Parte da dissertação de mestrado do primeiro autor.

${ }^{2}$ Universidade Federal de Mato Grosso, Faculdade de Medicina Veterinária, Programa de Pós-Graduação em Ciência Animal, Cuiabá, Mato Grosso, Brasil.

${ }^{3}$ Universidade Federal de Mato Grosso, Faculdade de Medicina Veterinária, Departamento de Ciências Básicas e Produção Animal, Cuiabá, Mato Grosso, Brasil.

${ }^{4}$ Universidade Federal de Mato Grosso, Faculdade de Medicina Veterinária, Departamento de Clínica Medica Veterinária, Cuiabá, Mato Grosso, Brasil.

${ }^{5}$ Universidade Federal de Mato Grosso, Faculdade de Medicina Veterinária, Departamento de Zootecnia e Extensão Rural, Cuiabá, Mato Grosso, Brasil.

${ }^{6}$ Universidade Federal de São João del Rei, Departamento de Zootecnia, Viçosa, Minas Gerais, Brasil.

*Endereço para correspondência: allanmesacasa@ hotmail.com
}

\section{RESUMO}

Objetivou-se avaliar níveis de inclusão da torta de girassol no lugar de farelo de soja, em suplementos múltiplos para bovinos, em pastejo, no período seco do ano, sobre o desempenho produtivo e viabilidade econômica. Foram utilizados 20 novilhos, Nelore, não castrados, com idade e peso médio inicial de 20 meses e $330,29 \mathrm{~kg}$, respectivamente, distribuídos em quatro piquetes de 1,6 ha cada, formados por Brachiaria brizantha cv. Marandu. O experimento foi composto por três períodos experimentais de 28 dias cada. Os tratamentos consistiram na inclusão da torta de girassol em níveis crescentes de: zero, 270, $540 \mathrm{~g} / \mathrm{kg}$ de suplemento, e uma mistura composta apenas por sal mineral ad libitum (controle). Os suplementos foram formulados para serem isoproteicos $(25 \%$ PB) e fornecidos na quantidade de 1,5kg/animal $/$ dia. As disponibilidades de matéria seca total e pontencialmente digestível foram de 2.248 e $1591 \mathrm{~kg} \mathrm{MS} / \mathrm{ha}$ respectivamente. O experimento foi estruturado em delineamento inteiramente casualizado, com 4 tratamentos e 5 repetições. Observou-se efeito significativo dos níveis de inclusão da torta de girassol em relação ao suplemento controle sobre o ganho médio diário (GMD). Economicamente, a inclusão da torta de girassol, em até $100 \%$ de substituição ao farelo de soja, não afetou o retorno financeiro e destacou-se como uma fonte de proteína viável para alimentação de bovinos na fase de recria.

Palavras-chave: farelo de soja, ganho de peso, novilhos, torta de girassol.

\section{SUMMARY}

The aim of study was to evaluate inclusion levels of sunflower cake a protein source to replace soybean meal in formulation of multiple supplements for grazing cattle during dry season on performance and economic viability. We used 20 steers, Nelore, non-castrated, with age and initial weights of 20 months and $330 \mathrm{~kg}$, distributed in four paddocks of 1.6 ha each, consisting of Brachiaria brizantha cv. Marandu. The experiment consisted of three experimental periods of 28 days each. The strategy adopted was the inclusion of sunflower cake in levels of 
zero, $270,540 \mathrm{~g} / \mathrm{kg}$ of supplement, and a mixture composed only of mineral salt ad libitum (control). Supplements were formulated to be isonitrogenous $(25 \% \mathrm{CP})$ and provided the amount of $1.5 \mathrm{~kg} / \mathrm{animal} / \mathrm{day}$. The availability of total dry matter and potentially digestible were 2248 and $1591 \mathrm{~kg} \mathrm{DM} / \mathrm{ha}$ respectively. The experiment was structured in a completely randomized design. Significant effect was observed $(\mathrm{P}<0.10)$ for levels of inclusion of sunflower cake in relation to supplement control over the average daily gain (ADG). However, animals supplemented with zero $\mathrm{g} / \mathrm{kg}$ sunflower cake had higher ADG $(0.650 \mathrm{~kg})$ compared to cattle supplemented with $270,540 \mathrm{~g} / \mathrm{kg}$ and control $(0.558 \mathrm{~kg} /$ day; $\quad 0.521 \mathrm{~kg} /$ day and $0.161 \mathrm{~kg} /$ day, respectively). Economically, inclusion of sunflower cake to $100 \%$ replacement of soybean meal did not affect financial return, standing out as a viable source of protein for cattle feed in the growing phase.

Keywords: soybean meal, weight gain, steers, sunflower cake.

\section{INTRODUÇÃO}

$\mathrm{O}$ processo de globalização da economia tem causado grandes mudanças em diversos setores do agronegócio. A produção de gado de corte no Brasil tem sido desafiada a estabelecer sistemas de produção capazes de produzir de forma eficiente, competitiva e sustentável. A cadeia produtiva de carne bovina utiliza as gramíneas como principal fonte de nutrientes e, por conseguinte, apresenta oscilações ao longo do ano devido à sazonalidade na produção forrageira, com grande produção no período das águas (até $80 \%$ ) e deficiência no período das secas, o que reflete na produção animal (ZANETTI et al., 2000).

Atualmente, a formulação de suplementos proteicos e múltiplos para bovinos em pastejo tem sido estudada, de modo a considerar as exigências dos micro-organismos quanto à proteína degradável no rúmen (PAULA et al., 2010), visto que a proteína sintetizada pelos micro-organismos ruminais é normalmente a principal fonte de proteína metabolizável para ruminantes. No entanto, além de atender à demanda por nutrientes nos suplementos, deve-se ter preocupação com os custos da suplementação, sobretudo, na aquisição dos ingredientes para tornar a estratégia viável.

Para Oliveira \& Cáceres (2005), a torta de girassol, subproduto das indústrias, obtida através da extração do óleo por processo mecânico (prensagem), é uma excelente fonte proteica e energética. Segundo Sottoriva (2010), a região Centro-Oeste é a mais promissora do país nessa cultura, chegou, por exemplo, a plantar 53 mil hectares e colher aproximadamente 80 mil toneladas, em 2004. Além disso, a cultura do girassol, por iniciar a safra em fevereiro e terminar em agosto, apresenta-se como uma opção de rotação, que é cada vez mais solicitada por produtores que buscam uma alternativa ao milho, no período da safrinha, com a vantagem de disponibilizar seus subprodutos no período de escassez de forragem (OLIVEIRA et al., 2007).

Porém, ressalta-se que ainda são escassos os estudos que utilizam a torta de girassol como fonte proteica para bovinos de corte sob pastejo. Dessa forma objetivou-se avaliar o desempenho animal e a viabilidade econômica da inclusão da torta de girassol em diferentes níveis, em substituição do farelo de soja, na formulação de suplementos múltiplos para bovinos, na fase de recria, mantidos sob pastejo, na época seca do ano. 


\section{MATERIAL E MÉTODOS}

$\mathrm{O}$ experimento foi conduzido no setor de Bovinocultura de Corte da Fazenda Experimental da Faculdade de Agronomia, Medicina Veterinária e Zootecnia - FAMEV da Universidade Federal de Mato Grosso - UFMT. A Instituição está localizada no município de Santo Antônio do Leverger - MT, próximo das coordenadas de $15^{\circ} 47^{\prime} 5^{\prime \prime}$ Sul e $56^{\circ} 04^{\prime}$ Oeste, com altitude de $140 \mathrm{~m}$, no período da seca, entre os meses de maio e agosto de 2010.

A área experimental, destinada aos animais de desempenho, possuía quatro piquetes de 1,6ha cada, cobertos uniformemente de capim Brachiaria. brizantha cv. Marandu, providos de bebedouros e cochos cobertos. As dimensões dos cochos de $60 \mathrm{~cm} /$ animal permitiram acesso de todos os animais simultaneamente. Para o estudo de desempenho foram utilizados 20 novilhos Nelore, não castrados, com idade e peso médio inicial de 20 meses e $330,29 \mathrm{~kg}$, respectivamente. No início da adaptação, todos os animais foram submetidos ao controle de endo e ectoparasitas, receberam vacinação contra clostridioses e contra febre aftosa. O delineamento experimental foi inteiramente casualizado, com 4 tratamentos e 5 repetições.

Foram avaliados três suplementos isoproteicos (25\% PB), constituídos de milho grão triturado, farelo de soja, torta de girassol, ureia e mistura mineral (Tabela 1), nos quais a torta de girassol foi incluída gradativamente em zero; $270 ;$ e $540 \mathrm{~g} / \mathrm{kg}$ de suplemento. As dietas foram formuladas previamente, segundo as exigências propostas pelo BR-Corte (2006), para um bovino zebuíno, macho inteiro, com $320 \mathrm{~kg}$ de peso corporal e com ganho médio diário de $500 \mathrm{~g} / \mathrm{dia}$ (exigência: $3,50 \mathrm{~kg} / \mathrm{dia}$ de NDT e $0,730 \mathrm{~kg} /$ dia de PB), conforme tabela 1 .

Os suplementos foram fornecidos diariamente, em quantidades de $1,5 \mathrm{~kg} / \mathrm{dia}$, em horário fixo, às dez horas da manhã. Os dados de precipitação pluviométrica e das temperaturas máxima e mínima, coletados no Instituto Mato-grossense de Meteorologia (INMET), durante o experimento, podem ser vistos na Tabela 2.

Tabela 1. Composição $(\mathrm{g} / \mathrm{kg})$ dos suplementos, com base na matéria natural

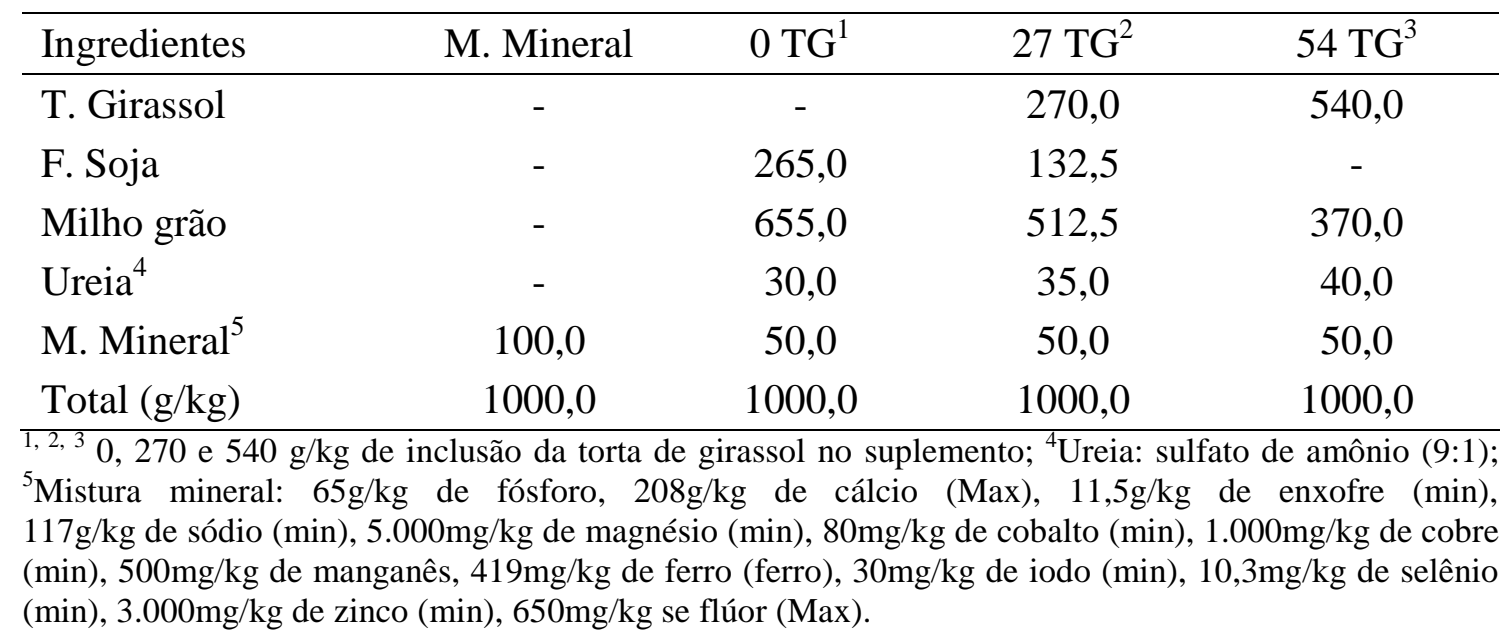


Rev. Bras. Saúde Prod. Anim., Salvador, v.13, n.4, p.1166-1179 out./dez., 2012 http://www.rbspa.ufba.br ISSN 15199940

Tabela 2. Valores médios das temperaturas máxima e mínima e precipitação pluviométrica, coletados no período de maio a agosto de 2010

\begin{tabular}{lccc}
\hline \multirow{2}{*}{ Mês } & \multicolumn{2}{c}{ Temp. Média $\left({ }^{\circ} \mathrm{C}\right)$} & \multirow{2}{*}{ Precipitação $(\mathrm{mm})$} \\
\cline { 2 - 3 } & Máxima & Mínima & 67,8 \\
\hline Maio & 30,2 & 17,4 & 0,0 \\
Junho & 32,8 & 16,0 & 8,5 \\
Julho & 30,5 & 14,5 & 0,0 \\
Agosto & 34,5 & 14,5 & 76,3 \\
\hline Total & - & - & \\
\hline
\end{tabular}

Os animais passaram por um período de adaptação de 15 dias, durante o mês de maio, receberam quantidades crescentes de suplemento que continha $270 \mathrm{~g} / \mathrm{kg}$ de torta de girassol $(0,5 ; 1$ e $1,5 \mathrm{~kg} / \mathrm{animal} / \mathrm{dia})$, até atingir a quantidade fixa final de fornecimento. O objetivo da adaptação foi evitar que o ganho compensatório de alguns animais pudesse influenciar no ganho de peso final $\mathrm{e}$ influenciar positivamente $\mathrm{o}$ resultado de ganho de peso do lote.

Os animais foram pesados no início (após adaptação) e final do experimento, após serem submetidos a jejum de sólidos de 12 horas, com objetivo de reduzir possíveis diferenças quanto ao enchimento do trato digestório. Posteriormente, à pesagem inicial, os animais foram estratificados com base no peso corporal (PC) e distribuídos, aleatoriamente, em quatro lotes, com pesos semelhantes, para evitar que a diferença média de peso dos animais que receberam suplemento não ultrapassasse $5 \mathrm{~kg} / \mathrm{lote}$.

A cada 28 dias, foi realizada a pesagem dos animais sem jejum prévio para monitorar o ganho de peso em função da qualidade da forragem com o avanço do período seco. Os bovinos foram rotacionados entre os piquetes, a cada 14 dias no intuito de reduzir possíveis variações entre a disponibilidade de matéria seca (MS) da forragem dos piquetes experimentais, de modo a manter o fornecimento dos mesmos suplementos aos animais até o final do período experimental. Os valores de peso inicial e final, com jejum de sólidos, foram utilizados para o cálculo de GMD, isto é, a divisão do ganho de peso total pelo tempo de duração do experimento em dias.

No primeiro dia de cada período experimental, foi realizada a coleta de pasto para determinação da disponibilidade total de matéria seca/ha, por meio do corte, ao nível do solo, de cinco áreas delimitadas por um quadrado metálico de $0,5 \mathrm{x} \quad 0,5 \mathrm{~m}$, escolhidas aleatoriamente em cada piquete experimental dos animais em desempenho. Após a pesagem, as amostras foram homogeneizadas por piquete e por período, em duplicata. Das amostras compostas de forragem, foram retiradas duas subamostras. Uma foi seca, em estufa de ventilação, forçada a $65{ }^{\circ} \mathrm{C}$, moída em moinho tipo Willey (peneira com orifícios de $1,0 \mathrm{~mm}$ de diâmetro), enquanto a outra foi utilizada para a separação dos componentes botânicos das plantas de Brachiaria brizantha: folha verde (FV), colmo verde (CV), folha seca (FS) e colmo seco (CS).

A avaliação da forragem ingerida pelos animais foi realizada por intermédio de simulação manual do pastejo, coletada no primeiro dia de cada período experimental. As amostras foram 
imediatamente pesadas após a coleta, congeladas a $-20^{\circ} \mathrm{C}$, posteriormente, foram descongeladas e secas em estufa de ventilação forçada a $65^{\circ} \mathrm{C}$ e moídas em moinho tipo Willey para análises químico-bromatológicas.

Amostras dos ingredientes e dos suplementos foram coletadas em todas as misturas, em seguida, foram congeladas a $-20^{\circ} \mathrm{C}$. Após o término do experimento de campo, foram descongeladas, homogeneizadas e delas foram retiradas subamostras para que fossem realizadas as análises laboratoriais.

As estimativas de oferta de matéria seca (kg MS/100kg PC) foram calculadas com a utilização da massa de forragem total média dos piquetes em cada período experimental, dividida pelo total médio de peso corporal animal mantido no mesmo período.

Das amostras destinadas à estimativa de massa de forragem (MF), foi determinado o resíduo insolúvel em detergente neutro, avaliado após incubação in situ das amostras, por 244 horas (FDNi), de acordo com Casali et al. (2008), para cálculo do percentual de MS potencialmente digestível (MSpD) disponível aos animais. Esse resultado foi estimado por intermédio da seguinte equação:

$\operatorname{MSpD}(\%$ da MS $)=0,98 \times(100-$ FDN $)$ $+($ FDN - FDNi); em que: $0,98=$ coeficiente de digestibilidade verdadeiro do conteúdo celular.

As determinações da matéria seca (MS), matéria orgânica (MO), proteína bruta (PB), fibra em detergente neutro (FDN), fibra em detergente ácido (FDA), FDN corrigida para cinza e proteína (FDNcp), extrato etéreo (EE) e matéria mineral (MM) dos ingredientes e da forragem foram realizadas de acordo com descrições de Silva e Queiroz (2002). A determinação do nitrogênio indisponível em detergente neutro
(NIDN) seguiu os métodos descritos por Van Soest et al. (1991). A quantificação dos carboidratos não fibrosos (CNF) dos suplementos foi realizada de acordo com adaptação de Hall (2000), em virtude da inclusão de ureia na composição dos suplementos, a saber:

$\mathrm{CNF}=100-[(\% \mathrm{~PB}-\% \mathrm{~PB}$ da ureia $+\%$ ureia) + FDNcp + \%EE + \%cinzas]; na qual: FDNcp= fibra em detergente neutro corrigida para cinza e proteína.

Os teores de carboidratos totais dos ingredientes (CT) foram calculados segundo Sniffen et al. (1992):

$\mathrm{CT}=100-(\% \mathrm{~PB}+\% \mathrm{EE}+\%$ Cinzas $)$

Os CNF da forragem foram calculados pela diferença entre os CT e FDNcp. A avaliação da viabilidade econômica dos suplementos foi realizada após a obtenção dos resultados de ganho de peso médio diário por animal $\mathrm{e}$ associada ao custo da suplementação com farelo de soja e torta de girassol. Todas as cotações empregadas foram realizadas na região de Cuiabá, no mesmo período de realização do experimento.

Foi realizada a avaliação da viabilidade econômica da suplementação, durante o ciclo de produção que se caracterizou pela compra dos animais no início do experimento até a venda dos mesmos, no término, baseada no peso, de modo a envolver todos os custos e receitas, os cálculos dos gastos com aquisição, alimentação, mão de obra, energia elétrica e sanidade. $O$ preço de aquisição foi baseado no peso corporal (PC), com 52\% de rendimento de carcaça e preço da arroba no período em que começou o experimento, e obtevese:

Lote Mineral: $((310,04 \mathrm{~kg}$ x $52 \%) / 15) \mathrm{x}$ $\mathrm{R} \$ 75,00)=\mathrm{R} \$ 806,104$; lote 0 TG: $((336,2 \mathrm{~kg} \times 52 \%) / 15) \times \mathrm{R} \$ 75,00)=$ R\$874,12; lote 27TG: $((335,14 \mathrm{~kg} \quad \mathrm{x}$ $52 \%) / 15) \times \mathrm{R} \$ 75,00)=\mathrm{R} \$ 871,364$, lote 
54 TG: $\quad((339,8 \mathrm{~kg} \quad \mathrm{x} \quad 52 \%) / 15) \quad \mathrm{x}$ $\mathrm{R} \$ 75,00)=\mathrm{R} \$ 883,48$

$\mathrm{O}$ custo com alimentação envolveu o custo dos suplementos e pasto. Os custos dos suplementos foram: lote Mineral: R\$0,07/animal/dia; lote 0 TG: $\mathrm{R} \$ 0,6861 /$ animal/dia; lote 27 TG: R\$0,6000/animal/dia; lote 54 TG: $\mathrm{R} \$ 0,5070 /$ animal/dia Os gastos que envolveram a pastagem foram realizados em função do custo médio de recuperação de 1,0ha de pasto, sem necessidade de intervenção mecânica no solo, apenas com calagem e adubação a lanço, por equipamento agrícola (espalhador); sem necessidade de adição de sementes ou mudança de espécie cultivada. Os valores utilizados foram baseados nas informações fornecidas pela empresa AGROCON - Consultoria e Planejamento em Agronegócio (Empresa Credenciada ao Banco do Brasil para Elaboração de Projetos de Investimento e Custeio Agropecuário). Os resultados encontrados foram: custo médio: R\$31,08/animal/ciclo.

O manejo sanitário considerou custos com vermifugação, vacinação contra febre aftosa, vacinação contra clostridioses e compra de larvicidas e repelente, cujos gastos foram: custo médio: $\mathrm{R} \$ 4,30 /$ animal/ciclo. $\mathrm{O}$ gasto com mão de obra foi calculado com base na condição real da fazenda onde se realizou o experimento, que possuía um funcionário disponível: custo médio: $\mathrm{R} \$ 910,00 /$ ciclo. O gasto com energia elétrica durante o processo de trituração e mistura foi contabilizado, em consideração aos valores médios de KWh em propriedades rurais, no qual foi encontrado: $\mathrm{R} \$ 30,00 /$ ciclo $\mathrm{O}$ custo operacional envolveu mão de obra, energia, e manejo sanitário.

Os dados coletados foram submetidos à análise de variância e teste de médias
Student Newman Kells (SNK). Para a variável ganho de peso médio diário, o peso inicial foi utilizado como covariável, porém como não era significativo $(p>0,05)$, o modelo foi reparametrizado, e os graus de liberdade a ele destinados foram incorporados ao resíduo. Utilizou o software estatístico SAS (2001), com nível de significância de $05 \%$.

\section{RESULTADOS E DISCUSSÃO}

A disponibilidade média de matéria seca total (DMST) foi aproximadamente $2.248 \mathrm{kgMS} / \mathrm{ha}$ (Tabela 3), situada abaixo da disponibilidade mínima preconizada por Moraes et al. (2010) de $2.500 \mathrm{~kg} \mathrm{MS} / \mathrm{ha}$, o que prejudica a seletividade dos animais em pastejo. Além disso, a taxa de lotação média utilizada ao longo dos períodos experimentais foi cerca de 2,36UA/ha.

A altura média do dossel forrageiro foi de $17,94 \mathrm{~cm}$. No primeiro período, a altura foi de $24,14 \mathrm{~cm}$, segundo período de $14,98 \mathrm{~cm}$, e terceiro período de $14,70 \mathrm{~cm}$. Tais valores estão situados abaixo do recomendado por Silva (2008) para manejo contínuo do capim Capim B. brizantha cv. Marandu, cujo ideal seria de 35 a $50 \mathrm{~cm}$.

A alta pressão de pastejo, associada à baixa oferta de forragem, prejudicou a seletividade dos animais e, consequentemente, a digestibilidade dos nutrientes. Essa combinação correlacionase negativamente com a digestibilidade da forrageira, de modo a não permitir que o bovino selecione porções mais nutritivas, como as lâminas foliares verdes, em detrimento dos colmos e de material senescente (BERCHIELLI et al., 2011). 
Rev. Bras. Saúde Prod. Anim., Salvador, v.13, n.4, p.1166-1179 out./dez., 2012 http://www.rbspa.ufba.br ISSN 15199940

Tabela 3. Valores médios para a matéria seca total (MST), matéria seca potencialmente digestível (MSpd), folha verde (FV), folha seca (FS), colmo verde (CV), colmo seco (CS) do capim-marandu Marandu; ao longo do experimento

\begin{tabular}{lcccccc}
\hline Material/Período & $\begin{array}{c}\text { MST } \\
(\mathrm{kg} / \mathrm{ha})\end{array}$ & $\begin{array}{c}\text { MSpd } \\
(\mathrm{kg} / \mathrm{ha})\end{array}$ & $\begin{array}{c}\text { FV } \\
(\%)\end{array}$ & $\begin{array}{c}\text { FS } \\
(\%)\end{array}$ & $\begin{array}{c}\text { CV } \\
(\%)\end{array}$ & $\begin{array}{c}\text { CS } \\
(\%)\end{array}$ \\
\hline Período 1 & 3383,10 & 2602,93 & 23,00 & 28,00 & 24,00 & 25,00 \\
Período 2 & 1657,00 & 1118,47 & 19,00 & 34,00 & 21,00 & 26,00 \\
Período 3 & 1705,55 & 1076,79 & 14,00 & 26,00 & 18,00 & 42,00
\end{tabular}

Período 1- 04/06/2010 a 02/07/2010; Período 2 - 03/07/2010 a 31/07/2010; Período 3 - 01/08/2010 a $29 / 08 / 2010$

Pastagens com DMST, inferiores a $2000 \mathrm{~kg}$ por hectare, promovem menor consumo de pasto e maior tempo de pastejo (SILVA et al., 2009). Verificouse que apenas no primeiro período, a DMST foi superior ao considerado mínimo para não prejudicar o desempenho dos animais.

A disponibilidade média de MSpd foi de $1599,39 \mathrm{~kg} \quad \mathrm{MS} / \mathrm{ha}$, número correspondente a cerca de $71 \%$ da DMST. Tal valor é semelhante ao encontrado por Paula (2010), 71,7\%, durante experimento no período da seca realizado na mesma área experimental, e superior ao observado por Moraes et al. (2010), durante experimento também no período seco do ano (49,59\%). Os valores de DMSpd superiores podem ser explicados pelo maior teor de colmo seco encontrado por Moraes et al. (2010), de aproximadamente 60,8\% contra $30,37 \%$ no presente estudo, que, de acordo com Berchielli et al. (2011), é o principal componente que interfere negativamente na qualidade $\mathrm{e}$ digestibilidade da forragem consumida, fator também evidenciado pelo menor teor de FDNi no presente estudo $(30,82 \%)$ ao observado pelos autores de $40,35 \%$.

Foi observado valor médio de 4,69\% de PB para Brachiaria brizantha cv. Marandu, obtida através da simulação de pastejo. Esse valor foi inferior ao encontrado por Paula (2010) - $(5,84 \%)$ e próximo aos encontrados por Manella et al. (2002) e Agulhon et al. (2005), que ao analisarem a forragem no período seco encontraram valores de $4,46 \%$ e $5,1 \%$ respectivamente. Os valores de PB situaram-se ao longo de todo o período experimental abaixo de $7 \%$ de $\mathrm{PB}$, que limita o desenvolvimento dos micro-organismos no rúmen $\mathrm{e}$, por conseguinte, prejudica a utilização da porção potencialmente degradável da FDN (PAULA, 2010).

$\mathrm{O}$ valor médio de FDN da forragem encontrado foi 77,39\%, próximo ao registrado por Agulhon et al. (2005), 72,70\%. De acordo Allen (1996), o teor de FDN é um dos fatores mais limitantes do consumo de volumosos, e os teores dos constituintes da parede celular superiores a 55\%-60\%, na massa seca, se correlacionam de forma negativa com o consumo de forragem. Para Berchielli et al. (2011), à medida que aumentam os teores de FDN e FDA, ocorre queda no valor nutritivo da forragem em função da menor concentração de conteúdo celular, o que limita a energia disponível ao animal. Esse efeito pode ser aqui observado através da queda significativa dos CNF, a partir do segundo período.

Além do teor de PB estar baixo, parte dessa proteína é de lenta degradação ou indisponível. O valor médio encontrado 
para o nitrogênio indisponível, em detergente neutro (NIDIN), foi $27,7 \%$, próximo ao observado por Baroni (2007), 29\%, e deve-se ressaltar que ocorreu elevação do valor ao longo do tempo. Em geral, a forragem apresentou ao longo do experimento, baixo valor nutritivo, fator atribuído, de acordo com Cabral et al. (2008), primariamente, às elevadas taxas de amadurecimento das gramíneas, que resultam no aumento dos teores dos constituintes fibrosos, tecidos lignificados, baixo conteúdo celular e compostos nitrogenados. Esse efeito pode ser observado na Tabela 4, pois os teores de FDNi e NIDN aumentaram ao longo do experimento, enquanto a PB decresceu.

Tabela 4. Teores médios de MS, MO, PB, EE, MM, FDN, FDNcp, FDNi, FDA, CT, CNF e NIDN, ao longo dos meses experimentais

\begin{tabular}{lcccc}
\hline Item & Junho & Julho & Agosto & Média \\
\hline MS (\%) & 37,59 & 43,20 & 47,00 & 42,59 \\
MO $^{1}$ & 90,00 & 91,33 & 92,62 & 91,32 \\
PB $^{1}$ & 6,30 & 4,63 & 3,14 & 4,69 \\
$\mathrm{EE}^{1}$ & 2,12 & 1,72 & 1,14 & 1,66 \\
$\mathrm{CZ}^{1}$ & 10,00 & 9,29 & 7,89 & 9,06 \\
$\mathrm{FDN}^{1}$ & 70,72 & 79,76 & 81,71 & 77,39 \\
$\mathrm{FDNcp}^{1}$ & 62,83 & 73,27 & 76,42 & 70,84 \\
$\mathrm{FDNi}^{1}$ & 22,48 & 33,48 & 36,51 & 30,82 \\
$\mathrm{FDA}^{1}$ & 34,55 & 42,92 & 45,59 & 41,02 \\
$\mathrm{CT}^{1}$ & 81,58 & 84,36 & 87,83 & 84,59 \\
$\mathrm{CNF}^{1}$ & 18,75 & 11,09 & 11,41 & 13,75 \\
$\mathrm{NIDN}^{2}$ & 24,70 & 27,80 & 30,60 & 27,70 \\
\hline
\end{tabular}

${ }^{1} \%$ Matéria seca; ${ }^{2} \% \mathrm{~N}$ total.

$\mathrm{MS}=$ matéria seca; $\mathrm{MO}=$ matéria orgânica; $\mathrm{PB}=$ proteína bruta; $\mathrm{EE}=$ extrato etéreo; $\mathrm{CZ}=$ cinzas; FDN = fibra em detergente neutro; FDNcp = fibra em detergente neutro corrigida para cinzas e proteína; FDNi = fibra em detergente neutro indisponível; FDA = fibra em detergente ácido; $\mathrm{CT}=$ carboidratos totais; $\mathrm{CNF}=$ carboidratos não fibrosos; NIDN = nitrogênio indisponível em detergente neutro.

Em virtude da falta de homogeneidade na extração do óleo do girassol, ocorre grande variação nos teores de PB e EE dos subprodutos, o que provoca dificuldade de caracterizá-los em torta ou farelos. Sousa (2008), ao pesquisar a viabilidade econômica do uso dos subprodutos do girassol para vacas leiteiras, encontrou teores de $22,09 \%$ e $30,19 \%$ de $\mathrm{PB}$; e $15,41 \%$ e $1,75 \%$ de EE para a torta e farelo, respectivamente. Domingues et al. (2010) observaram valores de 23,50\% PB para a torta.
Verificou-se aqui que os teores de PB da torta são mais elevados que os citados em algumas pesquisas, porém em função do alto teor de EE (Tabela 5) e do processo de extração da retirada do óleo na indústria (prensagem), onde o ingrediente foi adquirido, este é caracterizado como torta de girassol.

O elevado teor de EE, encontrado no ingrediente estudado, o caracteriza como uma fonte proteica e energética, mas para Ahmad et al. (2004), o teor elevado de fibras da torta, como foi 
Rev. Bras. Saúde Prod. Anim., Salvador, v.13, n.4, p.1166-1179 out./dez., 2012 http://www.rbspa.ufba.br ISSN 15199940

encontrado pode restringir sua mistura em rações, por acarretar redução no desempenho. De acordo com Garcia et al. (2006), níveis acima de $25 \%$ de FDA ou $40 \%$ de FDN começam a limitar o consumo de MS em função de restrições físicas.

Tabela 5. Composição química dos ingredientes e suplementos com base na matéria seca

\begin{tabular}{lrrrrrr}
\hline \multirow{2}{*}{ Itens } & \multicolumn{3}{c}{ Ingredientes } & \multicolumn{3}{c}{ Suplementos } \\
\cline { 2 - 7 } & Milho & F. soja & T.girassol & 0TG & 27TG & 54TG \\
\hline MS (\%) & 88,40 & 88,69 & 95,34 & 89,39 & 91,09 & 92,77 \\
MO $^{1}$ & 98,49 & 93,12 & 94,16 & 92,04 & 92,09 & 91,63 \\
PB $^{1}$ & 8,35 & 51,06 & 25,33 & 27,10 & 26,90 & 28,25 \\
EE $^{1}$ & 4,45 & 1,46 & 16,54 & 2,85 & 7,57 & 11,32 \\
CZ $^{1}$ & 1,51 & 6,88 & 5,84 & 7,96 & 7,91 & 8,37 \\
FDN $^{1}$ & 19,04 & 21,35 & 48,53 & 25,96 & 34,80 & 41,72 \\
FDNcp $^{1}$ & 15,60 & 17,26 & 40,32 & 18,31 & 25,51 & 29,59 \\
FDNi $^{1}$ & 0,78 & 2,35 & 22,75 & 2,07 & 7,75 & 12,75 \\
FDA $^{1}$ & 4,79 & 14,25 & 35,42 & 9,98 & 16,26 & 24,62 \\
CT $^{1}$ & 85,69 & 40,60 & 52,29 & 62,09 & 57,62 & 52,06 \\
CNF $^{1}$ & 70,09 & 23,34 & 11,97 & 48,66 & 34,72 & 26,43 \\
NIDN $^{2}$ & 22,57 & 12,80 & 34,00 & 18,20 & 19,44 & 21,45 \\
\hline
\end{tabular}

${ }^{1} \%$ da matéria seca; ${ }^{2} \%$ do $\mathrm{N}$ total.

$\mathrm{MS}=$ matéria seca; $\mathrm{MO}=$ matéria orgânica; $\mathrm{PB}=$ proteína bruta; $\mathrm{EE}=$ extrato etéreo; $\mathrm{CZ}=$ cinzas; FDN = fibra em detergente neutro; FDNcp = fibra em detergente neutro corrigida para cinzas e proteína; FDNi = fibra em detergente neutro indisponível; FDA = fibra em detergente ácido; $\mathrm{CT}=$ carboidratos totais; $\mathrm{CNF}$ = carboidratos não fibrosos; NIDN = nitrogênio indisponível em detergente neutro.

Não houve diferença estatística significativa $\quad(\mathrm{P}>0,05)$ entre os suplementos avaliados para o GMD, fator atribuído ao teor isoproteico dos suplementos e quantidades iguais de fornecimento aos bovinos (1,5kg/animal/dia). Entretanto, os animais que receberam suplementação múltipla apresentaram GMD, aproximadamente, $72 \%$ superior aos animais que receberam apenas mistura mineral como fonte suplementar. Comportamento semelhante, no que se refere à suplementação proteica de bovinos no período seco do ano, foi relatado por Detman et al. (2004). Esses estudiosos utilizaram 25 novilhos mestiços, holandês $\mathrm{x}$ zebu, com idade e peso médios iniciais de $367,7 \mathrm{~kg}$ e 24 meses, que recebiam suplementos com níveis crescentes de proteína e, paralelamente, o suplemento controle (Mistura Mineral), e observaram que todos os bovinos alimentados com suplementação proteica apresentaram desempenho superior ao grupo controle $(\mathrm{P}<0,01)$, em relação às variáveis GMD e PVF (Tabela 6).

Garcia et al. (2006), em experimento que avaliava a inclusão do farelo de girassol em até $45 \%$ em substituição ao farelo de soja, na dieta de bovinos leiteiros em crescimento, não verificaram efeito negativo sobre $o$ ganho de peso. Isso lhes permitiu concluir que o farelo de girassol pode ser utilizado com eficiência na alimentação de bovinos em fase de crescimento. 
A formulação da dieta foi previamente realizada, segundo as exigências propostas pelo BR-Corte (2006) para um bovino cujo perfil foi anteriormente citado (Tabela 1). Ao se considerar, ao longo do experimento, o peso médio dos animais que receberam suplementação de $360 \mathrm{~kg}$ de $\mathrm{PC}$ e o teor proteico médio da gramínea e dos suplementos de $4,69 \%$ e $27,40 \%$ PB, respectivamente, e um consumo médio que seguiu a equação do BR-CORTE (2006), para bovinos nelores $(\mathrm{CMS}=-$ $2,40011+0,02006 *$ PVM $+4,81946 *$ GMD) de aproximadamente $7,0 \mathrm{~kg}$ MS/animal/dia, o GMD obtido (576g/animal) foi superior ao estimado pelo BR-Corte (2006), que seria de aproximadamente $450 \mathrm{~g} / \mathrm{anima} / \mathrm{dia}$.

Tabela 6. Pesos corporais iniciais (PCI) e finais (PCF), valores médios para ganho de peso total (GPT), ganho médio diário (GMD)

\begin{tabular}{lrrrrr}
\hline \multirow{2}{*}{ Variáveis } & \multicolumn{4}{c}{ Suplementos } & \multirow{2}{*}{ CV $(\%)$} \\
\cline { 2 - 5 } & $0 \mathrm{TG}^{1}$ & $27 \mathrm{TG}^{2}$ & $54 \mathrm{TG}^{3}$ & \multicolumn{1}{c}{$\mathrm{SAL}^{4}$} & \\
\hline PCI $(\mathrm{kg})$ & 336,20 & 335,14 & 339,80 & 310,04 & 08,8605731 \\
PCF $(\mathrm{kg})$ & 390,80 & 382,00 & 383,60 & 323,60 & 10,4660533 \\
GPT $(\mathrm{kg})$ & 54,60 & 46,86 & 43,80 & 13,56 & 45,1842648 \\
GMD $(\mathrm{kg})$ & $0,650^{\mathrm{a}}$ & $0,558^{\mathrm{a}}$ & $0,521^{\mathrm{a}}$ & $0,161^{\mathrm{b}}$ & 45,3336679 \\
\hline
\end{tabular}

${ }_{1,2,3} 0 ; 270$ e $540 \mathrm{~g} / \mathrm{Kg}$ de inclusão proteína da torta de girassol; ${ }^{4}$ Controle.

${ }^{\mathrm{ab}}$ Letras diferentes na mesma linha indicam que houve diferença estatística pelo teste $\mathrm{SNK}, \alpha=0,05$.

O suplemento $54 \mathrm{TG}$, ainda que tenha apresentado maior teor proteico, resultou em ganho de peso inferior aos suplementos 0 TG e 27 TG, que continham o farelo de soja. Esse resultado pode ser explicado pela maior participação de compostos indisponíveis à microbiota (FDNi e NIDN) no suplemento que nos demais. Resultado semelhante foi observado por Zervoudakis et al. (2002), no qual o suplemento composto por farelo de soja promoveu ganho superior ao formulado com farelo de glúten de milho. Desse modo, com os resultados encontrados, a inclusão da torta de girassol na dieta de bovinos em pastejo, na fase de recria, em substituição ao farelo de soja, não prejudicou o desempenho. Antes tornou-se uma fonte proteica alternativa, de maneira a destacar os ganhos diários de aproximadamente 521g/animal/dia, com a utilização da torta como única fonte de proteína, essencial quando se busca intensificar o sistema de produção, com o uso de suplementos de custo mínimo.

A substituição de $100 \%$ do farelo de soja pela torta de girassol promoveu economia de $28,2 \%$ no custo do suplemento (GARCIA, 2001), reduziu os custos com a suplementação em $47,10 \%$, de maneira a substituir $45 \%$ do farelo de soja para bovinos em crescimento; valor superior ao encontrado no nível mais próximo desse estudo ( $27 \mathrm{TG}$ ), que foi de $13 \%$ de redução. A diferença percentual na redução dos custos pode ser explicada pela variação regional do preço dos ingredientes.

Ao considerar o resultado apresentado pela análise estatística, ou seja, média de ganho comum aos animais que receberam suplementação, o suplemento com inclusão de $100 \%$ de torta de 
Rev. Bras. Saúde Prod. Anim., Salvador, v.13, n.4, p.1166-1179 out./dez., 2012 http://www.rbspa.ufba.br ISSN 15199940

girassol, em substituição ao farelo de soja, foi $\mathrm{o}$ de melhor retorno econômico. Porém a Tabela 7 considera o ganho numérico de cada lote.

$\mathrm{O}$ resultado da análise econômica que envolveu apenas o ganho de peso e o custo do suplemento indica maior rentabilidade (capital arrecadado/capital investido) ao lote que recebeu apenas a mistura mineral, no qual para cada $\mathrm{R} \$ 1,00$ investido haveria retorno de
$\mathrm{R} \$ 5,66$ (Tabela 7). Quando a análise envolve os custos operacionais, os lotes que receberam suplementação apresentam maior rentabilidade. $\mathrm{O}$ lote do suplemento com mistura mineral, mesmo tendo um custo relativamente menor com a mão de obra, não foi viável, visto acarretar prejuízos ao produtor, no qual para cada $\mathrm{R} \$ 1,00$ investido, obteve-se $\mathrm{R} \$ 0,43$ de retorno.

Tabela 7. Valores médios para ganho de peso total/lote (GPT/lote), ganho bruto/lote (G.B/lote), índice de viabilidade econômica do tratamento/lote (IVET/lote), tratamento + custo operacional (VETC/lote), e retorno econômico da operação (RE), que envolveu a aquisição dos animais

\begin{tabular}{|c|c|c|c|c|}
\hline Especificação & M. Mineral & $0 \mathrm{TG}$ & $27 \mathrm{TG}$ & $54 \mathrm{TG}$ \\
\hline GPT/lote $-\mathrm{kg}$ & 67,80 & 273,00 & 234,30 & 219,00 \\
\hline Equivalente Carcaça/lote ${ }^{1} @$ & 2,35 & 9,46 & 8,12 & 7,59 \\
\hline $\mathrm{R} \$ / @$ & 85,00 & 85,00 & 85,00 & 85,00 \\
\hline G.B R $\$ /$ Lote $^{2}$ & 199,78 & 804,44 & 690,40 & 645,32 \\
\hline Custo do Tratamento/Lote R\$ & 35,28 & 288,16 & 252,00 & 212,94 \\
\hline $\begin{array}{l}\text { Resultado Econômico do } \\
\text { Tratamento/Lote R\$ }\end{array}$ & 164,50 & 516,28 & 438,40 & 432,38 \\
\hline I.V.E.T/Lote ${ }^{3} \mathrm{R} \$$ & 5,66 & 2,79 & 2,74 & 3,03 \\
\hline $\begin{array}{l}\text { Custo Tratamento + } \\
\text { Operacional/Lote } \mathrm{R} \$\end{array}$ & 463,55 & 716,44 & 680,28 & 641,22 \\
\hline $\begin{array}{l}\text { Resultado Econômico do } \\
\text { Tratamento+Operacional/Lote R\$ }\end{array}$ & $-263,77$ & 88,00 & 10,13 & 4,10 \\
\hline $\begin{array}{l}\text { IVE do Tratamento }+ \\
\text { Operacional/Lote }{ }^{4} \mathrm{R} \$\end{array}$ & 0,43 & 1,12 & 1,01 & 1,01 \\
\hline Receita Total/lote R\$ & $4.767,70$ & $5.757,75$ & $5.628,10$ & $5.651,70$ \\
\hline Despesas Total/Lote R\$ & $4.494,08$ & $5.087,04$ & $5.037,10$ & $5.037,10$ \\
\hline Resultado econômico/Lote ${ }^{5} \mathrm{R} \$$ & 273,62 & 670,71 & 591,00 & 614,60 \\
\hline R.E & 1,06 & 1,13 & 1,12 & 1,12 \\
\hline
\end{tabular}

IVE $=$ índice de viabilidade econômica.

${ }^{1}$ Rendimento de carcaça - 52\%; ${ }^{2}$ (Equiv. Carcaça*Preço da arroba R\$ 85,00); ${ }^{3}$ (2/custo suplemento);

${ }^{4}$ (2/custo suplemento+operacional); ${ }^{5}$ (receita total/despesa total).

Dentre os lotes que receberam suplementação, todos foram viáveis, e o suplemento 0TG, com $0 \%$ de inclusão da torta, apresentou maior retorno financeiro, porém exigiu maior capital disponível para investimento.
Verifica-se também que o incremento de animais no sistema promove queda nos custos, principalmente, na mão de obra, o que torna a atividade pecuária mais lucrativa, pois, como salienta Paula (2008), uma maior escala de 
produção reduz significativamente os custos operacionais.

Foi considerado o preço de compra e venda dos animais, ao fim do estudo, baseado no peso corporal e preço da arroba comercializada (prática comercial adotada pelos pecuaristas), na região, entre os meses de maio e agosto, de $\mathrm{R} \$ 75,00$ e 85,00, respectivamente, segundo dados dos frigoríficos de Cuiabá - MT. Baseado nesses valores e nos custos com alimentação (pasto + suplemento), foi realizada avaliação do retorno econômico da estratégia durante os 84 dias, da qual obteve-se retorno econômico positivo em todos os lotes cujos animais que receberam a suplementação apresentaram maior rentabilidade.

Ao se considerarem os dias necessários para que os animais atingissem $480 \mathrm{~kg}$, cujo peso médio inicial fosse de $330 \mathrm{~kg}$ $\mathrm{e}$, ao se considerarem os correspondentes GMD, observou-se que bovinos suplementados somente com mistura mineral necessitariam de 930 dias para alcançar os $480 \mathrm{~kg}$. Por outro lado, os animais suplementados com diferentes níveis de inclusão da torta de girassol alcançariam $\mathrm{o}$ peso de abate mais precocemente e necessitariam de 231; 269 e 290 dias, respectivamente para os animais que receberam os suplementos 0 TG; 27 TG e 54 TG, o que promoveria uma redução média de 665 dias para levá-los ao abate. Isso implicaria uma redução nos custos de R\$220,00/animal, em consideração apenas do preço médio de $\mathrm{R} \$ 10,00 /$ animal/mês de arrendamento em pastagens cobertas com Brachiaria brizantha cv. Marandu, no ano de 2010 na região de Cuiabá - MT.

A suplementação com $1,5 \mathrm{~kg} / \mathrm{animal} / \mathrm{dia}$ de suplemento múltiplo com $25 \%$ de PB para bovinos na fase de recria, em pastagem formada de capim Brachiaria. brizantha cv. Marandu, proporciona incremento de $0,41 \mathrm{~kg} /$ dia no ganho de peso se comparada à suplementação mineral. Nesse nível de suplementação, a torta de girassol pode substituir completamente o farelo de soja.

\section{REFERÊNCIAS}

AHMAD, T.; ASLAM, Z.; RASSOL, $S$.; Reducing fiber content of sunflower oil meal through treatment of enzimes produced from Arachnoitus SP. Journal of Animal Science, v.75, p.231-235, 2004.

AGULHON, R.A.; JOBIM, C.C.; BRANCO, A.F.; CALIXTO JÚNIOR, $M$. Fontes energéticas e níveis de suplementação para vacas em pastagem de capim-marandu (Brachiaria brizantha Hochst ex. A. Rich Stapf) no inverno. Revista Brasileira de Zootecnia, v.34, n.1, p.151-158, 2005.

ALLEN, M.S. Physical constraints on voluntary intake of forages by ruminants. Journal of Animal Science, v.74, p.3063-3075, 1996.

BARONI, C.E.S. Níveis de suplementação para novilhos da raça Nelore terminados a pasto na região centro-oeste durante $o$ período da seca. 2007.97 p. Dissertação (Mestrado em Zootecnia) - Universidade Federal de Viçosa, Viçosa.

BERCHIELLI, T.T.; PIRES, A.V.; OLIVEIRA, S.G. Nutrição de Ruminantes. 2.ed. Jaboticabal: FUNEP/UNESP, 2011. 
Rev. Bras. Saúde Prod. Anim., Salvador, v.13, n.4, p.1166-1179 out./dez., 2012 http://www.rbspa.ufba.br ISSN 15199940

VALADARES FILHO, S.C.; PAULINO, P.V.R.; MAGALHÃES, K.A. Exigências nutricionais de zebuínos e tabelas de composição de alimentos - BR CORTE. 1.ed. Viçosa: Universidade Federal de Viçosa, 2006. 142p.

CABRAL, L.S.; ZERVOUDAKIS, J.T.; COPPEDÊ, C.M.; SOUZA, A.L.; CARAMORI JUNIOR, J.G.; POLIZEL NETO, A.; OLIVEIRA, I.S.

Suplementação de bovinos de corte mantidos em pastagem de Panicum maximum cv. Tanzânia-1 no período das águas. Revista Brasileira Saúde Produção Animal [Online], v.9, n.2, p.293-302, 2008.

CASALI, A.O.; DETMANN, E.; VALADARES FILHO, S.C.; PEREIRA, J.C.; HENRIQUES, L.T.; FREITAS, S.G.; PAULINO, M.F. Influência do tempo de incubação e do tamanho de partículas sobre os teores de compostos indigestíveis em alimentos e fezes bovinas obtidos por procedimento in situ. Revista Brasileira de Zootecnia, v.37, n.2, p.335-342, 2008.

DETMANN, E.; PAULINO, M.F.; ZERVOUDAKIS, J.T.; CECON, P.R.; VALADARES FILHO, C.; GONÇALVES, L.C.; CABRAL, L.S; MELO, A.J.N. Níveis de proteína bruta em suplementos múltiplos para terminação de novilhos mestiços em pastejo durante a época seca: desempenho produtivo e características de carcaça.

Revista Brasileira de Zootecnia, v.33, n.1, p.169-180, 2004.

DOMINGUES, A.R.; SILVA, L.D.F.; RIBEIRO, E.L.A.; CASTRO, V.S.; BARBOSA, M.A.A.F.; MORI, R.M.; VIEIRA, M.T.L.; SILVA, J.A.O.

Consumo, parâmetros ruminais e concentração de uréia plasmática em novilhos alimentados com diferentes níveis de torta de girassol em substituição ao farelo de algodão. Ciências agrárias, v.31, n.4, p.1059-1070, 2010.

GARCIA, J.A.S. Farelo de girassol na alimentação de bovinos leiteiros em fase de crescimento. 2001. 57p. Tese (Doutorado em Zootecnia) Universidade Estadual Paulista, Jaboticabal, 2001.

GARCIA, J.A.S.; VIEIRA, P.F.; CECON, P.R.; SETTI, M.C.; McMANUS, C.; LOUVADINI, $\mathrm{H}$. Desempenho de bovinos leiteiros em fase de crescimento alimentados com farelo de girassol. Ciência Animal Brasileira, v.7, n.3, p.223-233, 2006.

\section{HALL, M.B. Calculation of non-} structural carbohydrate content of feeds that contain non-protein nitrogen. Gainesville: University of Florida, 2000. p.A-25. (Bulletin, 339).

MANELLA, M.Q.; LOURENÇO, A.J.; LEME, P.R. Recria de bovinos Nelore em pastos de Brachiaria brizantha com suplementação protéica ou com acesso a banco de proteína de Leucaena lecocephala. Desempenho animal. Revista Brasileira de Zootecnia, v.31, n.6, p.2274-2282, 2002.

MORAES, E.H.B.K.; PAULINO, M.F.; VALADARES FILHO, S.C.; MORAES, K.A.; DETMANN, E.; SOUZA, M.G. Avaliação nutricional de estratégias de suplementação para bovinos de corte durante a estação da seca. Revista Brasileira de Zootecnia, v.39, n.3, p.608-616, 2010.

OLIVEIRA, M.D.S.; CÁCERES, D.R. Girassol na alimentação de bovinos. Jaboticabal: Funep, 2005. 78p. 
Rev. Bras. Saúde Prod. Anim., Salvador, v.13, n.4, p.1166-1179 out./dez., 2012 http://www.rbspa.ufba.br ISSN 15199940

OLIVEIRA, M. Dal S.; MOTA, D.A.; BARBOSA, J.C.; STEIN, M.S.; BORGONOVI, F. Composição bromatológica e digestibilidade ruminal In Vitro de concentrados contendo diferentes níveis de torta de. Ciência Animal Brasileira, v.8, n.4, p.629-638, 2007.

PAULA, N.F.; ZERVOUDAKIS, J.T.; CABRAL, L.S.; CARVALHO, D.M.G.; HATAMOTO-ZERVOUDAKIS, L.K.; MORAES, E.H.B.K.; OLIVEIRA, A.A. Frequencia de suplementação e fontes de proteína para recria de bovinos em pastejo no período seco: desempenho produtivo e econômico. Revista Brasileira de Zootecnia, v.39, n.4, p.873-882, 2010.

SAS INSTITUTE. SAS user's guide: statiscs. Version 8.2. Cary, 2001. 1028p.

SILVA, D.J.; QUEIROZ, A.C. Análise de alimentos: métodos químicos e biológicos. Viçosa: Universidade Federal de Viçosa, 2002. 235p.

SILVA, F.F.; SA, J.F.; SCHIO, A.R.; ITAVO, L.C.V.; SILVA, R.S.;

MATEUS, R.G. Suplementação a pasto: disponibilidade e qualidade $\mathrm{x}$ níveis de suplementação x desempenho. Revista Brasileira de Zootecnia, v.38, p.371389, 2009.

SILVA, S.C. Fundamentos para o manejo do pastejo de plantas forrageiras dos gêneros Brachiaria e Panicum. Piracicaba: USP/ESALQ, 2008.

SNIFFEN, C.J; O'CONNOR, J.D.; VAN SOEST, P.J.; FOX, D.G.; RUSSELL, J.B. A net carbohydrate and protein system for evaluating cattle diets: II. Carbohydrate and protein availability. Journal of Animal Science, v.70, n.12, p.3562-3577, 1992.
SOTTORIVA, L. D.M.; Tecnologia de produção do girassol (Helianthus annus L.). Disponível em: $\langle$ http://www.livia.bio.br/blog/?p=71>. Acessado em: 15 ago. 2010.

SOUSA, C.C. Avaliação econômica parcial de dietas com o farelo e a torta de girassol, na alimentação de vacas leiteiras. 2008. 33f. Universidade Estadual Paulista (Dissertação Mestrado em zootecnia), Jaboticabal.

VAN SOEST, P.J.; ROBERTSON, J.B.; LEWIS, B.A.; Methods for dietary fiber, Neutral detergent fiber, and nonstarch polysaccharides in relation to animal nutrition. Journal of Dairy Science, v.74, n.10, p.3583-3597, 1991.

ZANETTI, M.A.; REZENDE, J.M.L.; SCHALCH, F.; MIOTTO, C.M.

Desempenho de novilhos consumindo suplemento mineral proteinado convencional ou com uréia. Revista Brasileira de Zootecnia, v.29, n.3, p.935-939, 2000.

ZERVOUDAKIS, J.T.; PAULINO, M.F.; DETMANN, E.; VALADARES FILHO, S.C.; LANA, R.P.; CECON, P.R. Desempenho de novilhas mestiças e parâmetros ruminais em novilhos, suplementados durante o período das águas. Revista Brasileira de Zootecnia, v.31, n.2, p.1050-1058, 2002.

Data de recebimento: 20/11/2011

Data de aprovação: 05/12/2012 